\title{
CUSTOMER PERCEPTIONS ON INTERNET BANKING INFORMATION PROTECTION
}

Authors:

André Redlinghuis ${ }^{1}$

Chris Rensleigh ${ }^{1}$

\section{Affiliations:}

${ }^{1}$ Centre for Information

and Knowledge

Management, University

of Johannesburg, South-Africa

\section{Correspondence to:}

Chris Rensleigh

email:

crensleigh@uj.ac.za

\section{Postal address:}

Department of

Information and Knowledge

Management, University of

Johannesburg, PO Box 524,

Auckland Park 2006, South

Africa

\section{Keywords:}

information protection;

Internet banking;

e-commerce; trust; security

Dates:

Received: 18 July 2010

Accepted: 02 Nov. 2010

Published: 07 Dec. 2010

How to cite this article:

Redelinghuis, A. \&

Rensleigh, C., 2010,

'Customer perceptions

on Internet banking

information protection',

SA Journal of Information

Management 12(1), Art.

\#444, 6 pages. DOI:

10.4102 /sajim.v12i1.444

This article is available at:

http:/ / www.sajim.co.za

(C) 2010. The Authors. Licensee: OpenJournals Publishing. This work is licensed under the

Creative Commons

Attribution License.

\section{ABSTRACT}

Background: South Africa has a well-developed and established banking system which compares favourably with those in many developed countries (e.g. USA), but also sets South Africa apart from many other emerging market countries like Egypt and Brazil. Four dominant banks, namely the Amalgamated Banks of South Africa (ABSA), Standard Bank, Nedcor and First National Bank (FNB) influence the South African banking environment. Internet banking has slowly been taking off in South Africa since 1996 as consumers are attracted to the convenience, safety and lower costs of doing banking online. Trust is a significant component of Internet banking and online services and products.

Objectives: This article has reported on the results of a survey (a close-ended questionnaire) that was conducted by alumni of the University of Johannesburg (UJ). The research problem for this study has been formulated as 'what are Internet banking customers' perception on information protection when using Internet banking services and products?'

Method: The methodology for this study falls on quantitative research. The research study consisted of a detailed literature review, followed by an empirical component which consisted of a quantitative questionnaire. The questionnaire used in this study consisted of eight sections covering biographical information, financial institution and Internet banking, Internet banking service quality and delivery, Internet banking functionality, Internet banking costs, Internet banking convenience and relationships, Internet banking trust and Internet banking security and information technology (IT).

Results: It was established that the findings of this research could assist financial institutions with fostering and building greater value adding relationships with their customers. These value-adding endeavours will ensure that customers experience and perceive their Internet banking experience to be enriching. Education and awareness campaigns are key focus areas financial institutions should continuously invest in. Information should be easily retrievable and communicated in a manner that makes sense to the diverse customer base, especially within South Africa with its diverse cultures and languages.

Conclusion: The final conclusion that could be reached is that Internet banking products and services will continue to grow across various divides and platforms as the Internet costs decrease in future, the growth of Internet related products and services such as Internet banking will increase.

\section{INTRODUCTION}

This article is based on a Master's dissertation that investigated Internet banking customers' perceptions on information protection when using Internet banking services and products. Various factors influence and shape the perceptions of trust with regards to Internet banking.

The evolution of the Internet has led to the establishment of various value-adding products and services such as Internet banking (IB). Internet banking has changed the formal banking landscape forever. Some may argue that Internet banking has positively affected the lives of many, through providing services in a more convenient, efficient and effective manner, 365 days a year.

However, the growth of the Internet has lead to the increase of various Information Technology (IT) problems and challenges. Today, individuals and organisations are faced with an increasing number of attacks via computer and Internet viruses, phishing scams and Internet hackers.

In this technological era, individuals and organisations must place greater emphasis on ensuring that their financial well-being and future are protected. The investment in adequate software and infrastructure has become critical to conduct financial transactions securely via the Internet. The level of security awareness should be increased and entrenched at various levels through comprehensive awareness and educational programmes.

Extensive Internet banking awareness campaigns have been launched, but the level to which these campaigns are successful is questionable.

\section{THE SOUTH AFRICAN BANKING LANDSCAPE}

According to Singh (2004:188) banking in South Africa can be traced back to Cape Town in the 1860s where it was influenced by both British and Dutch traditions. South Africa has a well-developed and established banking system which compares favourably with those in many developed countries like the USA, but also sets South Africa apart from many other emerging market countries like Egypt and Brazil. The Governor of the South African Reserve Bank (SARB) stated in 2004 that South Africa's 
banking industry has developed into a mature sector, with a moderate level of private-sector indebtedness and a first-rate regulatory and legal framework (Mboweni 2004:1). He further indicated that South African banks are well-managed and utilise sophisticated risk-management systems and corporate governance structures in conducting business.

The banks in South Africa are regulated in accordance with the principles set by the Basel Committee on Banking Supervision and comply with international best practise. Over the past few years, South African banking customers have gained access to online, real-time and nationwide access to banking products and services, 24 hours a day throughout the year. South Africa's relaxation of exchange controls has resulted in South Africa becoming an increasingly important financial centre.

Four banks, namely, (1) the Amalgamated Banks of South Africa (ABSA), (2) Standard Bank, (3) Nedcor and (4) First National Bank (FNB), mainly influence the South African banking environment. Research done by Mittner (2008) illustrates that ABSA currently holds the largest segment (31\%) of the market with Standard Bank on 26\%, Nedbank 20\% and FNB 16\%. The remaining $7 \%$ of the market is made up of various smaller banks offering services and products to niche markets (Whitfield 2002:188).

\section{INTERNET BANKING}

According to Singh (2004:187), businesses (large to small) are being impacted as a result of the influence of the Internet. Organisations have become leaner, more profitable and more competitive. In addition, banking services extend perfectly onto the Internet, as there are no queues, customers can bank at their leisure and obtain detailed information about services and products without being hurried by customers waiting in line.

South African Internet banking has gradually been taking off in since 1996. Consumers were attracted to the convenience, safety and lower costs of online banking. ABSA Bank was the first to offer online services, followed by Nedcor with Standard Bank, FNB and Mercantile Bank following soon after (Singh 2004:190).

South African financial institutions incorporate the latest and advanced security (hardware and software) mechanisms. Banks use advanced verification and authentication principles, incorporated with technologies such as Short Message Service (SMS). All these technologies are used to ensure that the user's Internet banking experience is safe and secure.

According to Bus (2007:1), South African banks' online services still lack maturity and in most cases they do not see the customer as king. In addition, banks do not fully understand the way customers experience banking websites, as customers generally do not have a platform on which to voice their frustrations with online services. Bus proposes that if banks want to improve customers' experiences, they should monitor and understand the individual customer's online experience by ensuring they have 'line of sight' to every user.

Data security and theft are still major headaches for financial institutions. The issue of data security is becoming significantly more important as the trend towards mobile banking is increasing. Phishing attacks, according to Knabe (2007:1), are increasing by the day. Knabe defines phishing as a criminal activity that uses social engineering techniques to extract personal information from computer users. Despite efforts to stop phishing attacks, the number of consumers influenced has doubled since 2004. Increasingly, however, most attacks fail at looting consumer bank accounts, but those users that fall prey to these scams are more targeted (Litan 2006:1).

Although Internet banking threats are ever present the technology offers its users an extensive range of benefits and opportunities. One of the greatest benefits that Internet banking offers its consumers is that of convenience. Consumers have the choice to do Internet banking from home or at their offices any time during the day or night. The annoyance of standing in long queues at bank branches to speak to financial consultants has been removed.

Empowering consumers to take control of their own financial situations is extremely beneficial. Consumers have the ability to create or delete beneficiaries, set up payment structures and view financial records at their own will. If customers manage their financial portfolio properly, Internet banking can provide definite costs benefits. Financial solutions and/or packages are often structured in such a way that makes Internet banking more lucrative to consumers. Internet banking also reduces the time taken to perform banking transactions. Not only is the absence of queues a benefit, but electronic banking forms are normally streamlined through simple and efficient processes.

\section{THE CONCEPT OF TRUST}

For Internet banking trust is a significant component of and online services and products. Defining the concept of trust is relatively complicated. Theorist and researchers from different disciplines, such as economics, sociology and philosophy, analyse trust in relation to particular aspects of personal motivation, social interactions and institutional arrangements. In most cases, discussions centre around two important features of trust: firstly, the social conditions under which trust becomes an issue requiring attention and secondly, the kinds of cognitive, affective and moral activities in which people engage when assessing the trustworthiness of another. An assessment of trustworthiness will inform actions based on trust or distrust, that is, a willingness to engage or to withdraw respectively (Smith 2005:2).

Clarke (2001:2) states that trust also differs depending on the relationship between parties. Clarke argues that trust may be relatively unimportant where risks that the parties are exposed to are limited and the elapsed time during the exposure is quite short or where the risks are well-known but insurance is taken into account in the costs. Where such factors do not exist, trust tends to be crucial for transactions to take place and relationships to develop. Araujo and Araujo (2003:3) defines trust as '...trust is the assured reliance on the character, ability, strength, or truth of someone or something...'.

If we consider Internet commerce, trust can be regarded as a judgement made by the user, based on general experiences being a customer. Trust in various Internet banking products and services can be fostered and created through various methods. Firstly, Virkkunen (2004:22) argues that institutional trust in banks is a fundamental source of trust in Internet banking services. Individuals trust banks and the services they offer, but not always the new channels that these services are offered in. Virkkunen states that banks have actively familiarised customers to electronic banking during a long service development process which started in the late 1970 s with the launch of cash dispensing automatic teller machines (ATMs).

Secondly, customers would argue that Internet banking is safe and trustworthy if the service received was reliable and stable. It is therefore crucial that the Internet banking service is functionally competent and error-free. Customers' first trial of the product or service plays a significant role in the creation of trust.

Thirdly, the influence of peer groups and the recommendations they make are also important in trust creation. Virkkunen (2004:23) argues that the role of peer group influence in the adoption of Internet banking is somehow limited. Due to vast technology exposure today, many customers do not have to hear of the experiences of their friends, as they have already had their 
own experiences in both Internet usage and the use of electronic banking services such as ATMs.

During Internet banking or general e-commerce transactions a customer navigates through a website of a vendor or financial institution and during this process they are often faced with several uncertainties, challenges and risks (Kim \& Prabhakar 2000:540). These uncertainties and risks can be classified into three main components, namely pre-purchase uncertainties, post-purchase uncertainties as well as technology related risks and uncertainties. If the relationship between the customer and financial institution are not managed effectively during these instances the trusting business relationship can severely be impacted. It therefore becomes imperative that considerable resource investment is needed to ensure that customers perceive greater competence and skill in the financial institution they are interacting with to ensure a trusting relationship is forged.

\section{RESEARCH RESULTS AND ANALYSIS}

The following section is a discussion of the results from the empirical research conducted for a master's study. A closeended questionnaire was developed that covered eight sections related to Internet banking. The sample population (across age groups ranging from 18 to over 50) for the questionnaire (survey) was selected by means of convenience sampling from the University of Johannesburg (UJ) alumni database. In total 138 alumni completed the survey and the results were analysed by the Statistical Consultation Services (StatCon) which is a statistical research unit within the UJ.

The questionnaire consisted of the following eight sections:

- Section A - Biographical information.

- Section B - Financial institution and Internet banking.

- Section C - Internet banking service quality and delivery.

- Section D - Internet banking functionality.

- Section E - Internet banking costs.

- Section F - Internet banking convenience and relationships.

- Section G - Internet banking trust.

- Section H - Internet banking security and IT.

\section{Research findings}

The following is a discussion of the findings for the eight sections of the questionnaire.

\section{Biographical information}

The first section of the questionnaire focused on the biographical information. The largest percentage $(44 \%)$ of the respondents fell within the $26-35$ age group followed by $21 \%$ in the $36-49$ group and $20 \%$ in the $18-25$ group with the remaining $15 \%$ in the $50+$ group. The sample group with the largest number $(89.7 \%)$ of Internet banking services and products users fell within the age category of 36-49. A component of the biographical section of the questionnaire focused on the respondents' academic qualifications. A significant segment (37\%) of the respondents was in possession of undergraduate degrees with $21 \%$ with honours degrees and 15.9\% Master's degrees. The respondent gender spread was in favour of the females with $56.5 \%$, but in terms of actual Internet banking usage males were the larger grouping with $61.7 \%$.

\section{Financial institutions and Internet banking}

This section of the questionnaire focused on aspects such as the respondents' preferred choice of financial institution and their frequency of doing Internet banking from a specific location, such as at work or at home. In total, $60.1 \%$ of the respondents indicated that they make use of Internet banking services and products. $45.4 \%$ of the respondents bank with ABSA Bank, $25.7 \%$ of the respondents bank with Standard Bank, $17.1 \%$ of the respondents bank with First National Bank and the remaining respondents were divided amongst Nedbank and other smaller banks. ABSA Bank has, since the late 1990s and early 2000s, made significant investments in the Internet banking sector; coupled with its long history in the banking sector, ABSA has built a solid customer base. It can therefore be argued that this large percentage of their strong customer base will make use of ABSA's Internet banking products and services.

The results highlighted that the respondents only make use of basic Internet banking products and services, such as balance enquiries $(28.2 \%)$, payments $(28.6 \%)$ and transfers $(28.6 \%)$. In addition, the results show that the respondents make use of Internet banking services and products as and when the need arises. This is seen as more relevant in the non-business environment where people do not have to make use of Internet banking on a daily basis. People therefore only make use of Internet banking when they need to make urgent payments, transfers or do enquiries.

An interesting result from this section of the survey was the fact that a large percentage of the respondents $(96 \%)$ would make use of Internet banking from locations such as Internet cafés. This is a surprising result, as Internet cafés' information technology is often more susceptible to Internet attacks, viruses and so forth. The risk that clients' banking details could be stolen, infiltrated or manipulated is therefore greatly enhanced.

Accessing Internet banking products and services once per month or week from work (Figure 1) and from home (Figure 2) still seems to be highly relevant and the most popular Internet banking choice. At work or at home customers are often aware that their computers run the latest security software and they can therefore do their basic banking tasks (i.e. paying accounts, doing transfers, etc.) over the Internet.

The use of wireless or mobile technologies to do Internet banking has also become increasingly popular due to its convenience and availability factors. A large percentage $(80.5 \%)$ of the respondents indicated that they make use of mobile or wireless technologies as and when the need arises.

\section{Internet banking service quality and delivery}

This section of the questionnaire explored the perceptions Internet banking clients have about Internet banking reliability, quality and the service levels found at 'brick-and-mortar' bank branches compared to that of Internet banking environments. The results clearly indicate that both male $(91 \%)$ and female $(100 \%)$ respondents felt that the Internet banking environments

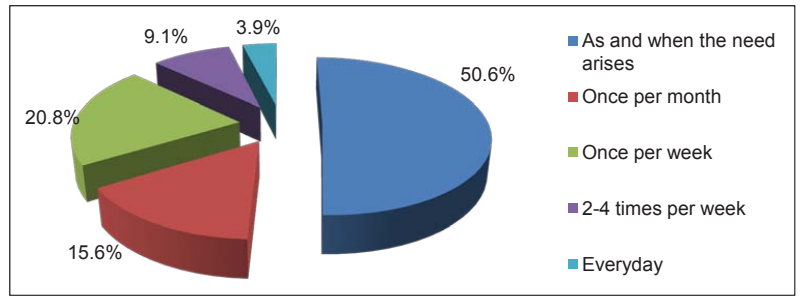

FIGURE 1

Internet usage from work

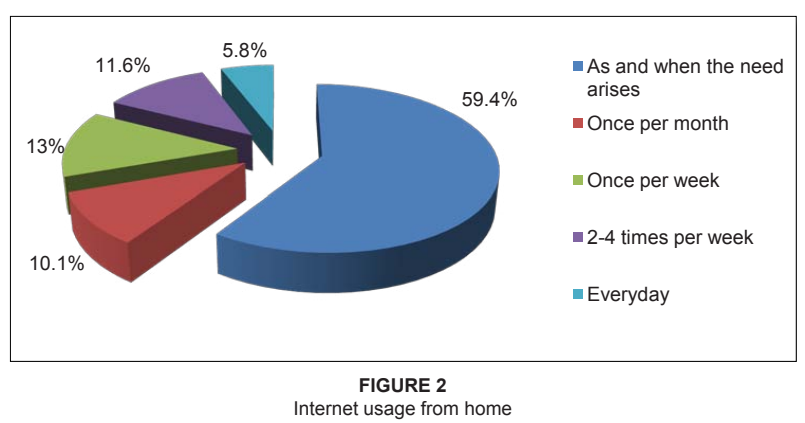




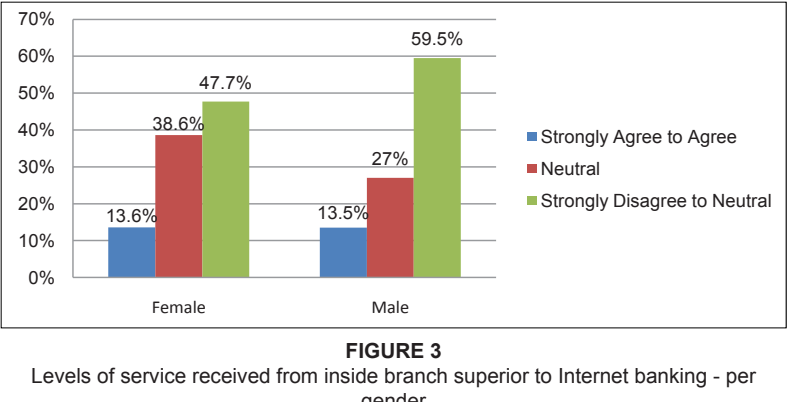

gender

are reliable. Both groups also indicated that the Internet banking service environment is of a high quality.

A large percentage of the respondents indicated that they believe that the services and products found within the Internet banking domain removes the need for them to visit a bank branch as $83 \%$ of the female respondents and $84 \%$ of the male respondents supported this fact. Although the neutral responses were relatively significant, both the female and male respondents stated that they believe that the level of service found within branches is not superior to that of Internet banking. The male respondents came out stronger in terms of this result (Figure 3).

The results of this section of the questionnaire highlighted key aspects that must be taken into consideration with regard to Internet banking service quality and delivery:

- If high quality standards are maintained in a bank branch, then these standards must be entrenched within Internet banking products and services, as some of these 'brick-andmortar' customers could make use of Internet banking in future.

- There is still a need for a 'brick-and-mortar' branch. Not all transactions can be carried out via the Internet without the involvement of a bank consultant or employee.

- Just one negative incident whilst doing Internet banking could be enough to change or damage the perception customers have of the Internet banking quality and service they received, thus creating the need for a 'brick-and-mortar' branch.

Service reliability and quality are key focus areas which banks should invest in as these 'softer' issues are the cornerstones to what shape the perceptions of clients whilst doing Internet banking related tasks.

\section{Internet banking functionality}

This component of the questionnaire investigated the underlying functionality that enhances the customers' Internet banking experience. Some of the questions revolved around user friendliness and Internet banking website layout.

A key aspect of Internet banking is the empowerment of its client base as clients should be able to fulfil most of their banking needs via any Internet-enabled platform to be or feel empowered. Whilst $95.2 \%$ of the respondents positively indicated that they are empowered due to the use of Internet banking, $4.8 \%$ of the respondents took a neutral stance. A strong percentage $(96.4 \%)$ of the respondents indicated that Internet banking allows them to perform all their basic banking needs.

To some extent a website's user friendliness as well as being purposeful and clear contributes to the quality and service perceptions of the customer. More than half $(55.4 \%)$ of the respondents indicated that the Internet banking websites they make use of are user-friendly and $62.7 \%$ indicated that the websites they use are purposeful and clear.

The output formats for transactions (such as balance enquiries and statements) were also investigated and a large percentage of the respondents $(94 \%)$ indicated that the information is easy to read and understand.

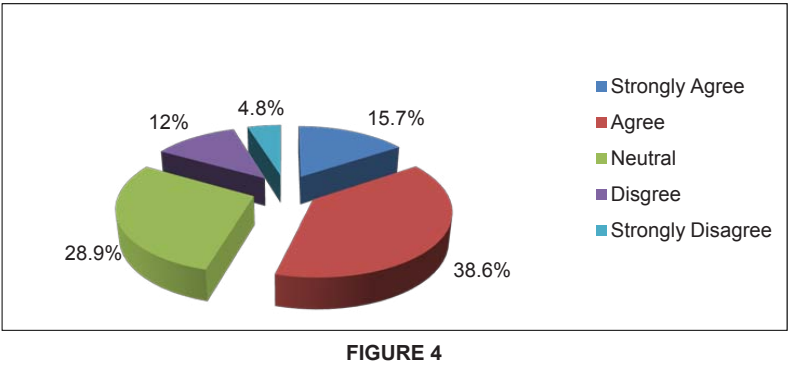

The money paid for Internet banking on a monthly basis is fair in relation to the services and products received

As online payments and transfers, as well as balance enquiries, are the Internet banking transactions performed more regularly it was critical to gage customers' satisfaction with these procedures and/or processes. Overall, $91.4 \%$ of the respondents indicated positive satisfaction levels in this regard.

The results of the questionnaire clearly show that customers need Internet banking to be user friendly and clear, but most importantly, that Internet banking functionality and technology should empower customers.

\section{Internet banking costs}

In these economic times, customers tend to make use of services and products they perceive to not only be cost effective, but that also have the most value for their Rand. The questionnaire results demonstrated that there was no significant difference between respondents in their belief that the fees they pay on a monthly basis are fair. Only $38.6 \%$ of the respondents agreed that the costs are fair, whilst a large percentage of the respondents $(28.9 \%)$ were uncertain and $16.8 \%$ indicated that they do not agree (Figure 4).

Most of the respondents (83.1\%) indicated (Figure 5) that it is more cost effective to make use of Internet banking than to visit a branch. Only $3.6 \%$ of the respondents did not agree, whilst $13.3 \%$ were neutral. In many cases customers tend to weigh the 'cost' of standing in line at a bank, driving to a bank, the risk of becoming a crime statistic when leaving a bank in relation to paying for Internet banking services and products and conducting Internet banking transactions in the comfort of their home or at an Internet café.

The results indicated that costs play a significant role in the adoption of Internet banking products and services. Customers want value for their money when it comes to Internet banking related products and services.

\section{Internet banking convenience and relationships}

The impact that Internet banking has on perceived convenience and fostering or building relationships can be termed as significant. The use of technology can often be seen as impersonal and not conducive to the establishment of long-term financial relationships.

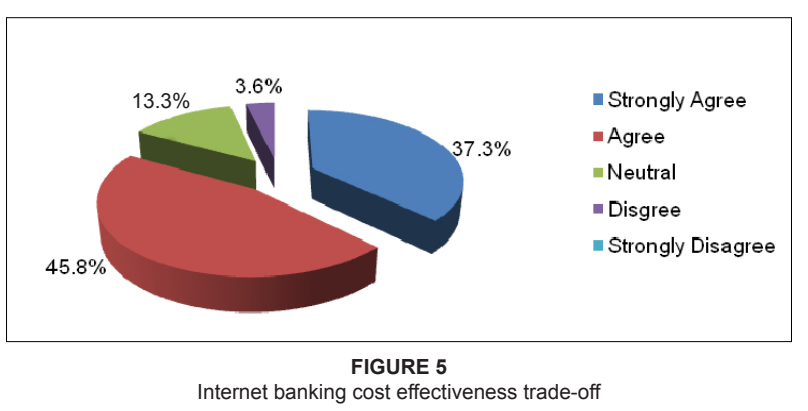




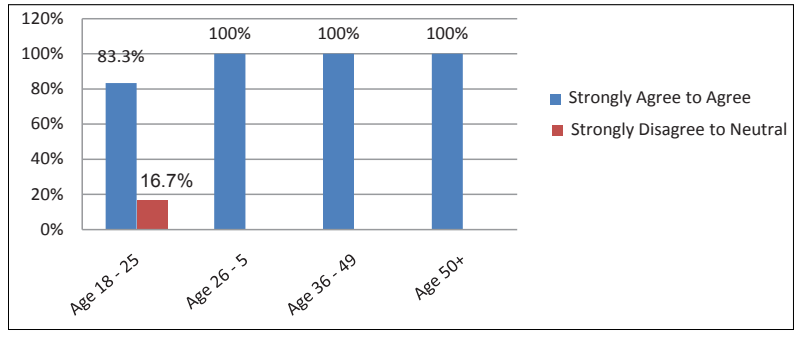

FIGURE 6

Internet banking is more convenient than traditional forms of banking - per age group

Nearly all of the respondents indicated (Figure 6) that Internet banking is more convenient than traditional forms of banking. This result also clearly aligns with previous analysis where respondents indicated that they prefer Internet banking over traditional forms of banking. Internet banking is in many instances more convenient as banking can be performed 24 hours a day from any location.

Understanding and meeting the needs of financial institutions' Internetbanking customers are keybuilding blocksin establishing a fruitful, long-term relationship. Financial institutions need to understand the advances in technologies in relation to the usage patterns and financial needs of its customers. All of the age categories confirmed that their Internet banking needs was met. These results highlight the need for financial institutions to better deliver on the needs of the Internet banking customer, especially in the younger age (18-25) segment. This could be a difficult task as the Internet banking clients formally interact with financial institutions (visit a branch) far less than in the past.

\section{Internet banking trust}

Within the questionnaire, trust was explored across critical areas, namely:

- financial and IT capabilities of the financial institution

- perceptions of trust created by acquaintances, colleagues and friends

- authentication or security processes

- history or journey of Internet banking.

The mindset created around a financial institution's IT and financial capabilities play a huge role in terms of trust. If customers generally perceive their banks financial and IT capabilities (i.e. performance and/or security) as secure, they will generally trust the services and products they make use of via this medium. The results show that across all age groups, the respondents trust the capabilities of their financial institution (Figure 7).

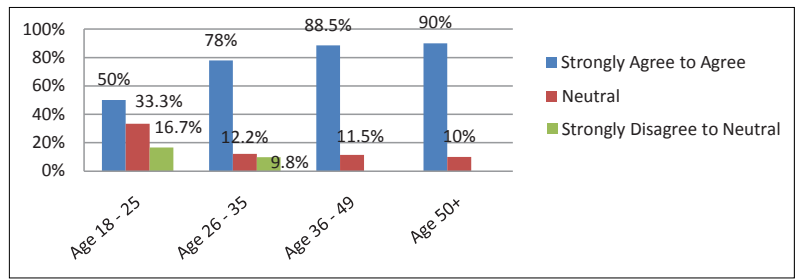

\section{FIGURE 7}

Internet banking done due to bank's financial \& Information Technology capabilities - pe age group

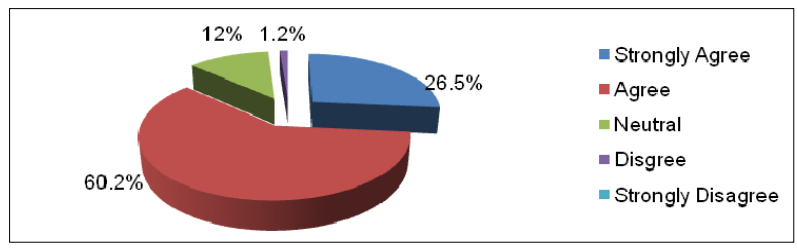

FIGURE 8

Trust in the Internet banking login and authentication process

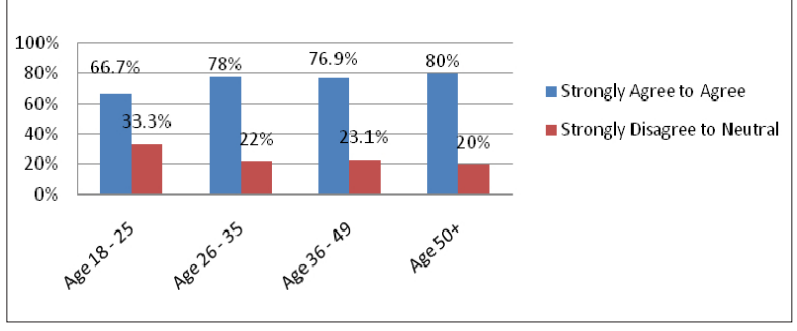

FIGURE 9

Internet banking maturity or growth - per age category

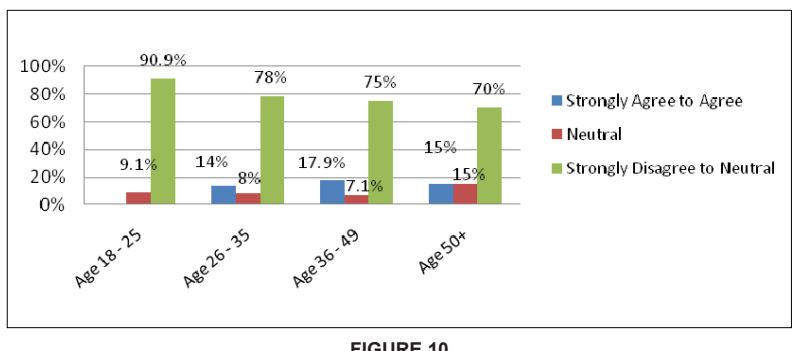

Safe to supply private information via email for banking purposes - per age group

No clear result could be obtained with regard to the influence respondents' families, friends and colleagues have on their trust of Internet banking products and services.

Internet banking fraud can take place during the log-in and authentication process. It has been found that in some cases clients are directed to a malicious Internet banking site that appears to be their own financial institution's Internet banking homepage. Once the customer logs on, their account details and passwords are intercepted and used for malicious purposes. The results highlight that Internet banking clients $(86.7 \%)$ have faith and trust that the login and authentication procedures they use are trustworthy (Figure 8).

The results show that Internet banking is currently perceived as more secure than a few years ago. Significant advances have been made within the Internet banking space regarding online security and many customers are reaping the rewards of this; all age groups supported this fact (Figure 9).

An interesting highlight of this section of the questionnaire is that $80.7 \%$ of the respondents indicated that they will make use of Internet banking even though they know of fraudulent instances that occurred via this medium. Reasons for this include:

- A breach of security has never happened to this specific client.

- They believe that they have the latest security software available and are vigilant when using the medium.

- They have great trust in their financial institution's ability to protect them from attacks.

It can thus be argued that the educational endeavours of financial institutions on Internet banking security principles are starting to pay off. Once again all the respondents indicated that it is not safe to supply personal banking details online (Figure 10). More could be done in this regard as roughly $13 \%$ of the respondents still believe that it is safe to send private banking information via email.

From Figure 10 it is clear that customer education by financial institutions should be a key focus area for further Internet banking developments.

Internet banking security and information technology This section highlights the impact that security and IT have on Internet banking levels of trust. Internet banking can be a risky endeavour, as many clients are faced with Internet attacks from 


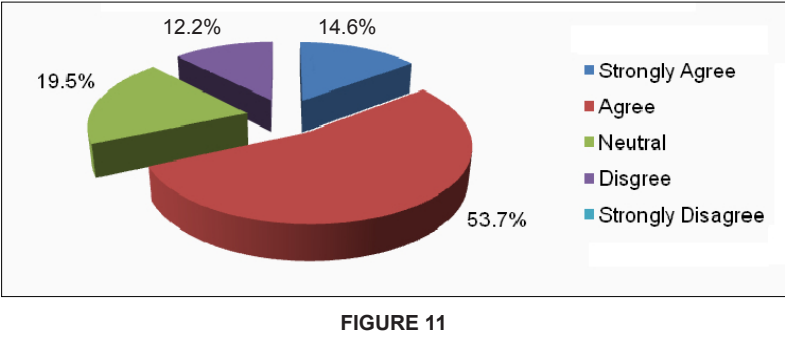

Security perception when using Internet banking

various sources. In some cases, clients are not well-equipped on an IT infrastructural level and these inadequacies also amplify the chances of being targeted by viruses, phishing attacks, individuals with malicious intent and so forth.

A significant percentage of the respondents $(68.3 \%)$ indicated that they feel secure when using Internet banking (Figure 11). Only $12.2 \%$ of the respondents indicated that they feel some level of insecurity.

A large percentage $(71.6 \%)$ of the respondents indicated that they believe that their financial institutions use the appropriate technologies to secure their financial information. This is an interesting result as most clients are not even aware of the types of technologies financial institutions have in place. Only $1.2 \%$ of the respondents disagreed with this statement, whilst $27.2 \%$ of the respondents were neutral on this matter.

Education and security awareness are topics often covered, albeit to a limited degree, by financial institutions. Often financial institutions have specific educational mechanisms to inform their clientele about the new Internet banking threats that exist. In many cases, the information is displayed when a client logs onto an Internet banking site to perform Internet banking transactions. The actual effectiveness of this information is uncertain. Financial institutions should educate their clients sufficiently, but the bank's clientele must also make use of the various opportunities given to them to broaden their knowledge with regard to Internet banking.

The results clearly highlighted that the respondents are not aware what hardware and software requirements they must comply with for Internet banking purposes as only $38.6 \%$ of the respondents indicated that they are aware of what hardware and software must be utilised.

This section highlighted that education is a critical factor with regard to Internet banking. Education should be a driving force from both parties, namely financial institutions as well as the individuals that make use of Internet banking services and products. A client's level of trust in Internet banking can be damaged rather quickly; the process involved with restoring the trust levels can take a significant amount of time.

\section{CONCLUSION}

The highlighted findings of this research could assist financial institutions with fostering and building greater value adding relationships with their customers. These value-adding endeavours will ensure that customers experience and perceive their Internet banking experience to be enriching.

As reflected within the findings the main users of Internet banking products and services are post-graduate students and customers mainly within the older age brackets. We are, however, seeing an increasing number of younger users requiring this service via more mobile, 'always-on' platforms such as cellular phones. Financial institutions will have to develop strategies to gain a piece of this growing market with totally different and varying needs.

Education and awareness campaigns are key focus areas which financial institutions should continuously invest in. Information should be easily retrievable and communicated in a manner that makes sense to a wider customer base, especially within the context of South Africa with its diverse cultures and languages.

Internet banking products and services will continue to grow across various divides and platforms. As Internet costs decrease in future, the growth of Internet related products and services such as Internet banking will increase.

\section{REFERENCES}

Araujo, I. \& Araujo, I., 2003, Developing trust in Internet commerce, School of Computer Science, Carleton University, Ottawa.

Bus, G., 2007, SA online banking lacks maturity, viewed 4 January 2010, from http://www.itweb.co.za

Clarke, R., 2001, Privacy as a means of engendering trust in cyberspace commerce, viewed 27 March 2010, from http:// www.austlii.edu.au/au/journals/UNSWLJ/2001/8.html

Kim, K. \& Prabhakar, B., 2000, Initial trust, perceived risk, and the adoption of Internet banking, Association for Computing Machinery, University of Cincinnati.

Knabe, A., 2007, Email phishing: Don't take the bait, viewed 1 May 2010, from http://newsblaze.com/story/20061017131115tsop. $\mathrm{nb} /$ topstory.html

Litan, A., 2006, Phishing attacks leapfrog despite attempts to stop them, viewed 14 May 2010, from http://www.gartner.com/ DisplayDocument?ref $=$ g_search\&id $=498301$

Mboweni, T., 2004, The South African banking sector - an overview of the past 10 years, viewed 15 March 2010, from http://www. bis.org/review/r041231f.pdf

Mittner, M., 2008, Debt: FNB, Standard suffers more, viewed 15 December 2009, from http://www.fin24.com

Singh, A., 2004, 'Trends in South African Internet banking', Aslib Proceedings 56(3), 187-196.

Smith, C., 2005, 'Understanding trust and confidence: Two paradigms and their significance for health and social care', Journal of Applied Philosophy 22(3), 299-316.

Virkkunen, T., 2004, Trust in the new economy - The case of Finnish banks, viewed 15 December 2009, from http://www.lvm.fi/ fileserver/trust\%20in\%20the\%20new\%20economy.pdf

Whitfield, B., 2002, Nedcor mulls free Internet access, viewed 15 December 2009, from http://allafrica.com/ stories/200205290504.html 